\title{
Ethnicity and other COVID-19 death risk factors in Mexico
}

Erwin Chiquete ${ }^{1}$, Jesus Alegre-Díaz ${ }^{2}$, Ana Ochoa-Guzmán ${ }^{1}$, Liz Nicole Toapanta-Yanchapaxi ${ }^{1}$, Carlos González-Carballo', Adrián Garcilazo-Ávila ${ }^{1}$, Rogelio Santacruz-Benitez ${ }^{1}$, Raúl Ramírez-Reyes ${ }^{1}$, Rosa María Wong-Chew³ ${ }^{3}$ Guadalupe Guerrero ${ }^{4}$, Max Schmulson², Jaime Berumen ${ }^{2,4}$, Valeria Sandoval-Rodríguez ${ }^{1}$, Eduardo Ruiz-Ruiz ${ }^{1}$, Carlos Cantú-Brito ${ }^{1}$

\author{
1Instituto Nacional de Ciencias Médicas y de la Nutrición "Salvador Zubirán”, \\ Mexico City, Mexico \\ ${ }^{2}$ Unidad de Investigación en Medicina Experimental, Universidad Nacional Autónoma \\ de México (UNAM), Mexico City, Mexico \\ ${ }^{3}$ Facultad de Medicina, Universidad Nacional Autónoma de México, Mexico \\ ${ }^{4}$ Hospital General de México “Dr. Eduardo Liceaga”, Mexico City, Mexico City, Mexico
}

Submitted: 30 August 2020; Accepted: 12 October 2020

Online publication: 4 December 2020

Arch Med Sci 2022; 18 (3): 711-718

DOI: https://doi.org/10.5114/aoms.2020.101443

Copyright (c 2020 Termedia \& Banach

\section{Abstract}

Introduction: Patients with severe acute respiratory syndrome coronavirus 2 (SARS-CoV-2) infection may develop coronavirus disease 2019 (COVID-19). Risk factors associated with death vary among countries with different ethnic backgrounds. We aimed to describe the factors associated with death in Mexicans with confirmed COVID-19.

Material and methods: We analysed the Mexican Ministry of Health's official database on people tested for SARS-CoV-2 infection by real-time reverse transcriptase-polymerase chain reaction (rtRT-PCR) of nasopharyngeal fluids. Bivariate analyses were performed to select characteristics potentially associated with death, to integrate a Cox-proportional hazards model.

Results: As of May 18, 2020, a total of 177,133 persons (90,586 men and 86,551 women) in Mexico received rtRT-PCR testing for SARS-CoV-2. There were 5332 deaths among the 51,633 rtRT-PCR-confirmed cases (10.33\%, 95\% Cl: 10.07-10.59\%). The median time (interquartile range, IQR) from symptoms onset to death was 9 days (5-13 days), and from hospital admission to death 4 days (2-8 days). The analysis by age groups revealed that the significant risk of death started gradually at the age of 40 years. Independent death risk factors were obesity, hypertension, male sex, indigenous ethnicity, diabetes, chronic kidney disease, immunosuppression, chronic obstructive pulmonary disease, age $>40$ years, and the need for invasive mechanical ventilation (IMV). Only 1959 (3.8\%) cases received IMV, of whom 1893 were admitted to the intensive care unit ( $96.6 \%$ of those who received IMV).

Conclusions: In Mexico, highly prevalent chronic diseases are risk factors for death among persons with COVID-19. Indigenous ethnicity is a poorly studied factor that needs more investigation.

Key words: atypical pneumonia, coronavirus, COVID-19, ethnicity, Mexico, pandemics.

\section{Introduction}

After the first confirmed case in Brazil on February 26, 2020, within a few weeks the coronavirus disease 2019 (COVID-19) pandemic was also reported in all territories of Latin America [1]. This pandemic has
Corresponding author: Carlos Cantú-Brito MD, PhD Instituto Nacional de Ciencias Médicas y de la Nutrición "Salvador Zubirán" Mexico City, Mexico Phone: (52) 5487-0900 ext. 5052 E-mail: carloscantu_brito@ hotmail.com 
E. Chiquete, J. Alegre-Díaz, A. Ochoa-Guzmán, L.N. Toapanta-Yanchapaxi, C. González-Carballo, A. Garcilazo-Ávila, R. Santacruz-Benitez, R. Ramírez-Reyes, R.M. Wong-Chew, G. Guerrero, M. Schmulson, J. Berumen, V. Sandoval-Rodríguez, E. Ruiz-Ruiz, C. Cantú-Brito

been challenging for the already overburdened public healthcare systems of the region [2-5]. Latin America suffers from severe inequalities, and public healthcare systems are the only source of medical care for a large sector of the population who work in the informal economy [6]. Hence, in the months to come it will be seen whether Latin America can cope with the sanitary and economic challenges of the COVID-19 pandemic.

Patients with the severe acute respiratory syndrome coronavirus 2 (SARS-CoV-2) infection may develop COVID-19, which has caused more than 1 million deaths worldwide to date [7]. Risk factors associated with death may vary between countries with different ethnical backgrounds [8-15]. These risk factors have been poorly described in Latin America, which represents a barrier to establishing proper epidemiological and clinical decisions to reduce the toll caused by this worrisome pandemic. Moreover, the lack of knowledge on clinical and epidemiological characteristics of the COVID-19 burden in neighbouring nations can introduce a factor of vulnerability for subsequent local epidemic waves, which usually obey mainly regional factors. Hence, it is critical to understand the factors associated with the outcome of COVID-19 in order to implement preventive and opportune treatment strategies to reduce the very high burden of this disease. Mexico is among the top five countries with the highest COVID-19 death tolls in the world [7].

Therefore, we aimed to describe the factors associated with death in persons with confirmed COVID-19 in Mexico.

\section{Material and methods}

We analysed the May 18, 2020, Ministry of Health's official daily database on all people tested for SARS-CoV-2 infection by real-time reverse transcriptase-polymerase chain reaction (rtRT-PCR) of nasopharyngeal fluids, for the clinical suspicion of COVID-19, in Mexico [16]. All patients who arrive at Mexican institutions dedicated to COVID-19 care are included in this official database, which is updated on a daily basis. This primary database contains information of basic demographics and traditional risk factors, such as obesity, hypertension, diabetes, asthma, chronic obstructive pulmonary disease (COPD), chronic kidney disease (CKD), immunosuppression, and other factors. A secondary electronic database was constructed for the present analysis, selecting case records with confirmed SARS-CoV-2. We excluded records with rtRT-PCR results pending, as well as those with negative results. A consent disclaimer was obtained for the aim of this analysis. This database was analysed without personal identifications, hospital record numbers, social security numbers, or contact details. All patients included in this database signed an informed consent for hospitalisation and for SARS-CoV-2 testing at the institution of origin.

\section{Statistical analysis}

Relative frequencies are expressed as percentages. Normally distributed continuous variables are expressed as means with standard deviations (SD). Non-parametric continuous variables are expressed as medians with interquartile range (IQR). Pearson's $\chi^{2}$ was used to assess proportions in nominal variables for bivariate analyses. Student's t-test and Mann-Whitney $U$-test were performed to compare quantitative variables between two groups, in normal and non-normally distributed variables, respectively. Bivariable analyses were performed to select variables potentially associated with death to integrate a Cox-proportional hazards model adjusted for relevant epidemiological and clinical characteristics. Hazard ratios (HR) with 95\% confidence intervals $(\mathrm{Cl})$ are provided. Actuarial analyses with the Kaplan-Meier method were also performed to assess the time to death after the initiation of COVID-19 symptoms. A $p \leq 0.05$ was considered as significant, and all $p$-values were two-tailed.

\section{Results}

As of May 18, 2020, a total of 177,133 persons (90,586 men and 86,551 women) in Mexico received rtRT-PCR testing of nasopharyngeal fluids for the presence of the SARS-CoV-2 genome (Table I). There were 51,633 cases with confirmed SARSCoV-2 infection (Table II), and 125,500 cases with rtRT-PCR results pending $(26,933)$ or negative results $(98,567)$ (Table III).

There were 7997 deaths among the whole cohort (case fatality rate, $\mathrm{CFR}=4.52 \%, 95 \% \mathrm{Cl}: 4.42-$ 4.61\%): 5332 deaths among COVID-9-confirmed cases (CFR $=10.33 \%, 95 \% \mathrm{Cl}: 10.07-10.59 \%$ ), 2009 deaths among persons with negative tests results (CFR $=2.04 \%, 95 \% \mathrm{Cl}: 1.95-2.13 \%)$, and 656 deaths in persons with pending results (case fatality rate: $2.44 \%, 95 \% \mathrm{Cl}: 2.26-2.63 \%$ ) (test for homogeneity: $p<0.001)$. The median time (interquartile range, IQR) from COVID-19 symptoms onset to death was 9 days (5-13 days), and from hospital admission to death was 4 days (2-8 days).

The analysis by age groups revealed that a markedly significant risk of death begins at the age of 40 years (Figure 1). Age, sex, and traditional risk factors (i.e. obesity, hypertension, diabetes, CKD, smoking, COPD, and cardiovascular disease among other factors) were associated with death in bivariate analyses (Table IV). To test the statisti- 
Table I. Demographic characteristics and risk factors of the whole population tested for SARS-CoV-2 infection in Mexico, by sex (as of May 18, 2020)

\begin{tabular}{|c|c|c|c|}
\hline Variable & $\begin{array}{c}\text { All } \\
(n=177,133)\end{array}$ & $\begin{array}{c}\text { Women } \\
(n=86,551)\end{array}$ & $\begin{array}{c}\text { Men } \\
(n=90,582)\end{array}$ \\
\hline Age, mean (SD) [years] & $40.9(17.0)$ & $41.9(16.7)$ & $43.2(17.3)$ \\
\hline Age, median (IQR) [years] & $39(29-51)$ & $40(30-52)$ & $42(31-54)$ \\
\hline \multicolumn{4}{|l|}{ Age [years], $n(\%)$ : } \\
\hline$<20$ & $10,694(6.0)$ & $5119(5.9)$ & $5575(6.2)$ \\
\hline $20-39$ & $70,821(40.0)$ & $36,246(41.9)$ & $34,575(38.2)$ \\
\hline $40-59$ & $67,530(38.1)$ & $32,897(38.0)$ & $34,633(38.2)$ \\
\hline $60-79$ & $23,751(13.4)$ & $10,214(11.8)$ & $13,537(14.9)$ \\
\hline$\geq 80$ & $4337(2.4)$ & $2075(2.4)$ & $2262(2.4)$ \\
\hline \multicolumn{4}{|l|}{ Risk factors, $n(\%)$ : } \\
\hline Hypertension & $30,462(17.2)$ & $14,509(16.8)$ & $15,953(17.6)$ \\
\hline Obesity & $29,083(16.4)$ & $14,897(17.2)$ & $14,186(15.7)$ \\
\hline Diabetes & $23,455(13.2)$ & $10,959(12.7)$ & $12,496(13.8)$ \\
\hline Smoking & $16,441(9.3)$ & $5401(6.2)$ & $11,040(12.2)$ \\
\hline Asthma & $6857(3.9)$ & $4182(4.8)$ & $2675(3.0)$ \\
\hline Cardiovascular disease & $4867(2.7)$ & $2222(2.6)$ & $2645(2.9)$ \\
\hline Chronic kidney disease & $4060(2.3)$ & $1752(2.0)$ & $2308(2.5)$ \\
\hline Chronic obstructive pulmonary disease & $3813(2.2)$ & $1816(2.1)$ & $1997(2.2)$ \\
\hline Immunosuppression & $3714(2.1)$ & $1925(2.2)$ & $1789(2.0)$ \\
\hline Invasive mechanical ventilation, $n(\%)$ & $3527(2.0)$ & $1225(1.4)$ & $2302(2.5)$ \\
\hline Intensive care unit, $n$ (\%) & $3813(2.2)$ & $1352(1.6)$ & $2461(2.7)$ \\
\hline Death, $n(\%)$ & $7997(4.5)$ & $2759(3.2)$ & $5238(5.8)$ \\
\hline Indigenous ethnicity, n (\%) & $1977(1.1)$ & $954(1.1)$ & $1023(1.1)$ \\
\hline
\end{tabular}

$I Q R$ - interquartile range, $S D$ - standard deviation.

cal independency of the association of covariables with CFR, we proceeded with an adjusted multivariate analysis. Thus, in a Cox proportional-hazards model controlled for relevant epidemiological and clinical antecedents, the risk factors associated with death were obesity, hypertension, male sex, self-reported indigenous ethnicity, diabetes, CKD, immunosuppression, COPD, age > 40 years, and the need for IVM (Figure 2). Only 1959 (3.8\%) cases received invasive mechanical ventilation (IMV), among whom 1893 were admitted to the intensive care unit $(96.6 \%$ among those who received IMV).

\section{Discussion}

This study shows that in Mexico, highly prevalent chronic diseases [17-20] are associated with COVID-19 death among persons with confirmed SARS-CoV-2 infection. It was notable that indig- enous ethnicity, an already recognised factor of vulnerability since the beginning of the COVID-19 pandemic [21-24], is a significant risk factor for death in the Mexican population. This factor may be related with limited access to a specialised health care within the indigenous communities, to different attitudes towards this specific pandemic, or to lack of knowledge on the COVID-19 spread and epidemiological behaviour in small communities of Mexico. Hence, this critical finding needs more analysis in future studies. To the best of our knowledge, this is one of the first reports about Amerindian ethnicity as a risk factor for death in patients with COVID-19 in Latin America [3, 25].

Although widespread, the COVID-19 pandemic has burdened some populations more than others, and there are growing concerns that minority groups could be disproportionately affected [26-28]. In this line of evidence, in the United States early data from New York 
E. Chiquete, J. Alegre-Díaz, A. Ochoa-Guzmán, L.N. Toapanta-Yanchapaxi, C. González-Carballo, A. Garcilazo-Ávila, R. Santacruz-Benitez, R. Ramírez-Reyes, R.M. Wong-Chew, G. Guerrero, M. Schmulson, J. Berumen, V. Sandoval-Rodríguez, E. Ruiz-Ruiz, C. Cantú-Brito

Table II. Demographic characteristics and risk factors of the population with positive test results for SARS-CoV-2 infection in Mexico, by sex (as of May 18, 2020)

\begin{tabular}{|c|c|c|c|}
\hline Variable & $\begin{array}{c}\text { All } \\
(n=51,633)\end{array}$ & $\begin{array}{c}\text { Women } \\
(n=21,830)\end{array}$ & $\begin{array}{c}\text { Men } \\
(n=29,803)\end{array}$ \\
\hline Age, mean (SD) [years] & $46.6(15.8)$ & $45.9(16.0)$ & $47.2(15.7)$ \\
\hline Age, median (IQR) [years] & $46(35-57)$ & $45(34-56)$ & $46(36-58)$ \\
\hline \multicolumn{4}{|l|}{ Age [years], $n(\%)$ : } \\
\hline$<20$ & $1222(2.4)$ & $588(2.7)$ & $634(2.1)$ \\
\hline $20-39$ & $17,031(33.0)$ & $7626(34.9)$ & 9405 (31.6) \\
\hline $40-59$ & $22,616(43.8)$ & $9319(42.7)$ & $13,297(44.6)$ \\
\hline $60-79$ & $9426(18.3)$ & 3699 (16.9) & $5727(19.2)$ \\
\hline$\geq 80$ & $1338(2.6)$ & $598(2.7)$ & $740(2.5)$ \\
\hline \multicolumn{4}{|l|}{ Risk factors, $n(\%)$ : } \\
\hline Hypertension & $11,151(21.6)$ & $4839(22.2)$ & $6312(21.2)$ \\
\hline Obesity & $10,708(20.7)$ & $4869(22.3)$ & $5839(19.6)$ \\
\hline Diabetes & $9460(18.3)$ & 3965 (18.2) & $5495(18.4)$ \\
\hline Smoking & $4366(8.5)$ & $1157(5.3)$ & $3209(10.8)$ \\
\hline Asthma & $1602(3.1)$ & $929(4.3)$ & $673(2.3)$ \\
\hline Cardiovascular disease & $1381(2.7)$ & $579(2.7)$ & $802(2.7)$ \\
\hline Chronic kidney disease & $1265(2.4)$ & $500(2.3)$ & $765(2.6)$ \\
\hline Chronic obstructive pulmonary disease & $1131(2.2)$ & $520(2.4)$ & $1611(2.1)$ \\
\hline Immunosuppression & $849(1.6)$ & 409 (1.9) & $440(1.5)$ \\
\hline Invasive mechanical ventilation, $n(\%)$ & $1959(3.8)$ & $586(2.7)$ & $1373(4.6)$ \\
\hline Intensive care unit, $n(\%)$ & $1893(3.7)$ & $596(2.7)$ & $1297(4.4)$ \\
\hline Death, $n(\%)$ & $5332(10.3)$ & $1696(7.8)$ & $3636(12.2)$ \\
\hline Indigenous ethnicity, $n$ (\%) & $739(1.4)$ & $284(1.3)$ & $455(1.5)$ \\
\hline
\end{tabular}

$I Q R$ - interquartile range, SD - standard deviation.

City suggested that death rates from COVID-19 among African American people (92.3 deaths per 100,000 population) and Hispanic people (74.3 deaths per 100,000 population) were substantially higher than in Caucasian (45.2 deaths per 100,000 population) or Asian patients (34.5 deaths per 100,000 population) [27]. Moreover, the UK's Institute for Fiscal Studies (IFS) reported that COVID-19 patients from ethnic minorities are younger than the white British patients, but patients from ethnic minorities have higher death rates [28]. After adjusting for age, sex, and geography, the authors of the IFS study found that CFR of patients from African ancestry is 3.5 times higher than that of white British people, while in those patients of black Caribbean and Pakistani ancestry, death rates were 1.7 and 2.7 times higher, respectively [28].

As we have shown in this study, other publications have reported that chronic diseases such as diabetes, asthma, hypertension, chronic kidney disease, air pollution, and obesity are associated with a high risk of infection and death in COVID-19 patients [10-15, 29-31]. These conditions occur and tend to converge more frequently in older people, but in the middle-aged population (aged 40-55 years) many other possible explanations emerge as to why they are also at high risk of death, when compared with younger persons aged $<40$ years, even when they may be free of prevailing chronic diseases. Background genetic susceptibility and a differential gene expression influenced by different respiratory conditions may play a role [32, 33], but social factors that may increase exposition to infection can also be considered, such as the middle-aged people living in densely-populated areas where economic activities abound, more frequent usage of public transportation, and employment in informal or low-paid jobs without sick pay insurance, among other factors [34]. 
Table III. Characteristics of the population with pending or negative test results for SARS-CoV-2 infection in Mexico, by sex (as of May 18, 2020)

\begin{tabular}{|lccc|}
\hline Variable & $\begin{array}{c}\text { All } \\
(n=125,500)\end{array}$ & $\begin{array}{c}\text { Women } \\
(n=64,721)\end{array}$ & $\begin{array}{c}\text { Men } \\
(n=60,779)\end{array}$ \\
\hline Age, mean (SD) [years] & $42.6(17.2)$ & $40.6(16.7)$ & $41.2(17.5)$ \\
\hline Age, median (IQR) [years] & $41(29-51)$ & $39(29-50)$ & $40(29-52)$ \\
\hline Age [years], $n$ (\%): & & & \\
\hline$<20$ & $9472(7.5)$ & $4531(7.0)$ & $4941(8.1)$ \\
\hline 20-39 & $53,790(42.9)$ & $28,620(44.2)$ & $25,170(41.4)$ \\
\hline $40-59$ & $44,914(35.8)$ & $23,578(36.4)$ & $21,336(35.1)$ \\
\hline 60-79 & $14325(11.4)$ & $6515(10.1)$ & $7810(12.8)$ \\
\hline$\geq 80$ & $2999(2.4)$ & $1477(2.3)$ & $1522(2.5)$ \\
\hline Risk factors, $n$ (\%): & & & \\
\hline Hypertension & $19,311(15.4)$ & $9670(14.9)$ & $9641(15.9)$ \\
\hline Obesity & $18,375(14.6)$ & $10,028(15.5)$ & $8347(13.7)$ \\
\hline Diabetes & $13,995(11.2)$ & $6994(10.8)$ & $7001(11.5)$ \\
\hline Smoking & $12,075(9.6)$ & $4244(6.6)$ & $7831(12.9)$ \\
\hline Asthma & $5255(4.2)$ & $3253(5.0)$ & $2002(3.3)$ \\
\hline Cardiovascular disease & $3486(2.8)$ & $1643(2.5)$ & $1843(3.0)$ \\
\hline Chronic kidney disease & $2795(2.2)$ & $1252(1.9)$ & $1543(2.5)$ \\
\hline Chronic obstructive pulmonary disease & $3682(2.1)$ & $1296(2.0)$ & $1386(2.3)$ \\
\hline Immunosuppression & $2865(2.3)$ & $1516(2.3)$ & $1349(2.2)$ \\
\hline Invasive mechanical ventilation, $n$ (\%) & $1568(1.2)$ & $639(1.0)$ & $929(1.5)$ \\
\hline Intensive care unit, $n$ (\%) & $1920(1.5)$ & $756(1.2)$ & $1164(1.9)$ \\
\hline Death, $n$ (\%) & $2665(2.1)$ & $1063(1.6)$ & $1602(2.6)$ \\
\hline Indigenous ethnicity, $n(\%)$ & $1238(1.0)$ & $670(1.0)$ & $568(0.9)$ \\
\hline
\end{tabular}

$I Q R$ - interquartile range, $S D$ - standard deviation.

The healthcare system in Mexico was already fragile when the first reported death from COVID-19 occurred on March 18, 2020, the day when the first 118 cases had been confirmed [16]. Moreover, health care fragmentation and segmentation are important problems for the complex and vulnerable sanitary system in Mexico [35]. This factor may also impose a challenge to the COVID-19 frontline, because Mexico has high rates of hypertension, obesity, and diabetes, all of which are risk factors for severe disease after SARS-CoV-2 infection in Mexicans [11, $12,36]$. The prevalence of this comorbid risk factors rises in adults with vulnerable social conditions, who have limited access to quality health care, and are characterised by high poverty levels [35]. Identification of risk factors for relevant clinical outcomes is of utmost importance to design specific therapies and to select effectively the most vulnerable populations to administer preventive measures, vaccination, and better health care [37-41].

The present study has limitations that need discussion for the correct interpretation of the present findings. Firstly, this database contains

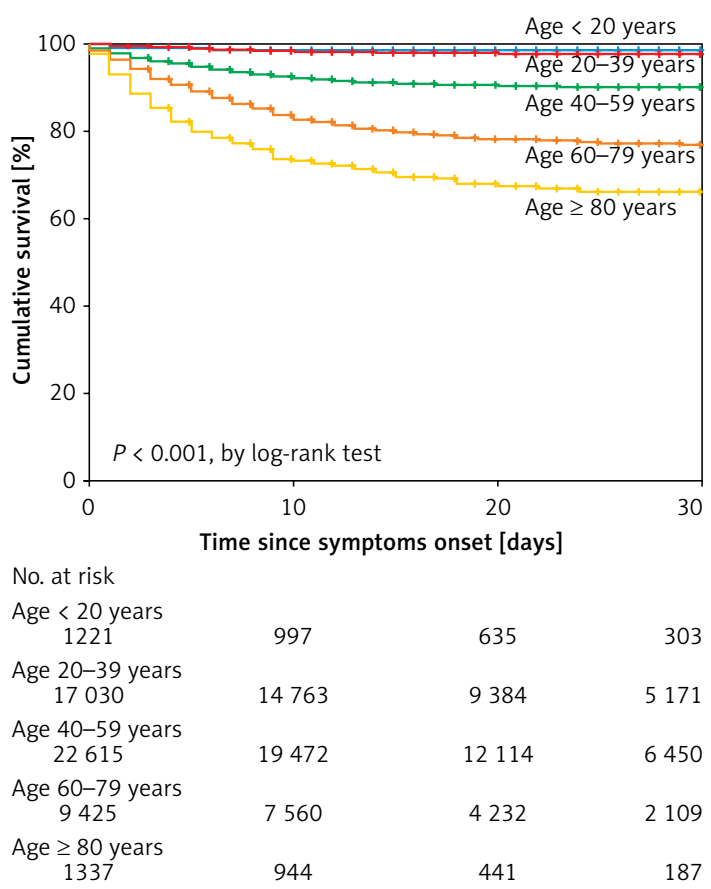

Figure 1. Actuarial analysis with the Kaplan-Meier method on age categories and 30-day survival in Mexican patients confirmed with COVID-19 by RT-PCR for SARS-CoV-2 (Secretaría de Salud, México) 
E. Chiquete, J. Alegre-Díaz, A. Ochoa-Guzmán, L.N. Toapanta-Yanchapaxi, C. González-Carballo, A. Garcilazo-Ávila, R. Santacruz-Benitez, R. Ramírez-Reyes, R.M. Wong-Chew, G. Guerrero, M. Schmulson, J. Berumen, V. Sandoval-Rodríguez, E. Ruiz-Ruiz, C. Cantú-Brito

Table IV. Bivariate analyses on risk factors associated with death in patients with COVID-19 in Mexico, by sex (as of May 18, 2020)

\begin{tabular}{|c|c|c|c|c|}
\hline Variable & $\begin{array}{c}\text { All } \\
(n=51,633)\end{array}$ & $\begin{array}{c}\text { Survivors } \\
(n=46,301)\end{array}$ & $\begin{array}{c}\text { Non survivors } \\
(n=5332)\end{array}$ & $P$-value \\
\hline Age, mean (SD) [years] & $46.6(15.6)$ & $45.2(15.3)$ & $59.5(14.1)$ & $<0.001$ \\
\hline Age, median (IQR) [years] & $46(35-57)$ & $44(34-55)$ & $60(50-69)$ & $<0.001$ \\
\hline Age [years], $n(\%)$ : & & & & $<0.001$ \\
\hline$<20$ & $1222(2.4)$ & $1201(2.6)$ & $21(0.4)$ & \\
\hline $20-39$ & $17,031(33.0)$ & $16,651(36.0)$ & $380(7.1)$ & \\
\hline $40-59$ & $22,616(43.8)$ & $20,371(44.0)$ & $2245(42.1)$ & \\
\hline $60-79$ & $9426(18.3)$ & $7159(15.5)$ & $2267(42.5)$ & \\
\hline$\geq 80$ & $1338(2.6)$ & $919(2.0)$ & $419(7.9)$ & \\
\hline Male sex, $n(\%)$ & $29,803(57.7)$ & $26,167(56.5)$ & $3636(68.2)$ & $<0.001$ \\
\hline \multicolumn{5}{|l|}{ Risk factors, $n(\%)$ : } \\
\hline Hypertension & $11,151(21.6)$ & $8886(19.2)$ & $2265(42.5)$ & $<0.001$ \\
\hline Obesity & $10,708(20.7)$ & $9262(20.0)$ & $1446(27.1)$ & $<0.001$ \\
\hline Diabetes & $9460(18.3)$ & $7398(16.0)$ & $2062(38.7)$ & $<0.001$ \\
\hline Smoking & $4366(8.5)$ & $3852(8.3)$ & $514(9.6)$ & 0.001 \\
\hline Asthma & $1602(3.1)$ & $1474(3.2)$ & $128(2.4)$ & 0.002 \\
\hline Cardiovascular disease & $1381(2.7)$ & $1070(2.3)$ & $311(5.8)$ & $<0.001$ \\
\hline Chronic kidney disease & $1265(2.4)$ & $862(1.9)$ & $403(7.6)$ & $<0.001$ \\
\hline Chronic obstructive pulmonary disease & $1131(2.2)$ & $798(1.7)$ & $333(6.2)$ & $<0.001$ \\
\hline Immunosuppression & $849(1.6)$ & $672(1.5)$ & $177(3.3)$ & $<0.001$ \\
\hline Invasive mechanical ventilation, $n(\%)$ & $1959(3.8)$ & $758(1.6)$ & $1201(22.5)$ & $<0.001$ \\
\hline Intensive care unit, $n(\%)$ & $1893(3.7)$ & $982(2.1)$ & $911(17.1)$ & $<0.001$ \\
\hline Indigenous ethnicity, $n(\%)$ & $739(1.4)$ & $596(1.3)$ & $143(2.7)$ & $<0.001$ \\
\hline
\end{tabular}

$I Q R$ - interquartile range, $S D$ - standard deviation.

$\begin{array}{lccccc}\text { Risk factor } & \begin{array}{c}\text { Risk factor present } \\ \text { No. of patients who died/total } n(\%)\end{array} & \text { Risk factor absent } & \text { Hazard ratio }(95 \% \text { Cl) } \\ \text { Obesity } & 1446 / 10708(13.5) & 3886 / 40925(9.5) & 1.31(1.19-1.43) \\ \text { Hypertension } & 2225 / 11151(20.3) & 3067 / 40482(7.6) & 1.48(1.35-1.62)\end{array}$

Figure 2. Analyses of risk factors associated with death in 51,633 Mexican patients confirmed with COVID-19 by RT-PCR for SARS-CoV-2 (Secretaría de Salud, México): a Cox-proportional hazards model

self-reported information on risk factors, comorbidities, and demographic characteristics, without laboratory or imaging information to confirm or even identify new putative mortality risk factors. Although this database is updated on a daily basis by comprehensive collaboration of all sanitary institutions, it depends essentially on passive testing performed in hospitals when people seek medical care, and as a consequence, this database cannot be considered as truly representative of the whole Mexican population. Moreover, although in Mexico self-reported indigenous 
ancestry is considered as reliable [42], no genetic ancestry informative markers were obtained to confirm that ethnicity - and not only social disparities - is linked with the risk of death, which is a major finding of our study. A new analysis is currently under preparation to test, from the medical and epidemiological perspective, whether ethnicity is associated with major COVID-19 risks through social inequalities and limited quality health care.

In conclusion, highly prevalent chronic comorbidities are risk factors for COVID-19 death in Mexico. Indigenous ethnicity is a significant death risk factor in Mexicans, and therefore, this critical finding requires analysis in future studies.

\section{Acknowledgments}

We would like to thank all frontline nurses, medical residents, and volunteer colleagues of the Instituto Nacional de Ciencias Médicas y Nutrición Salvador Zubirán, who are our true heroes in this fight. We are also thankful for the Mexican Ministry of Health's work to complete the recollection of the open data used in this report.

\section{Conflict of interest}

The authors declare no conflict of interest.

\section{References}

1. Rodriguez-Morales AJ, Gallego V, Escalera-Antezana JP, et al. COVID-19 in Latin America: the implications of the first confirmed case in Brazil. Travel Med Infect Dis 2020; 35: 101613.

2. Ponce-de-León A, Galindo-Fraga A, Ruiz-Palacios G, Sifuentes-Osornio J. Wuhan: back to the future and the return of Coronaviruses. Rev Invest Clin 2020; 72: 5-7.

3. Baqui P, Bica I, Marra V, Ercole A, van der Schaar M. Ethnic and regional variations in hospital mortality from COVID-19 in Brazil: a cross-sectional observational study. Lancet Glob Health 2020; 8: e1018-26.

4. Cruz-Pacheco G, Bustamante-Castañeda JF, Caputo JG, Jiménez-Corona ME, Ponce-de-León-Rosales S. Dispersion of a new coronavirus SARS-CoV- 2 by airlines in 2020: temporal estimates of the outbreak in Mexico. Rev Invest Clin 2020; 72: 138-43.

5. Ornelas-Aguirre JM. The new coronavirus that came from the East: analysis of the initial epidemic in Mexico. Gac Med Mex 2020; 156: 1-9.

6. Litewka SG, Heitman E. Latin American healthcare systems in times of pandemic. Dev World Bioeth 2020; 10.1111/dewb.12262.

7. COVID-19 Dashboard by the Center for Systems Science and Engineering (CSSE) at Johns Hopkins University (JHU): https://coronavirus.jhu.edu/map.html. Accessed: September 27, 2020.

8. Liu C, Huang Q, Wang P, et al. COVID-19 disease: novel clinical manifestations and therapeutic exploration. Arch Med Sci 2020. doi:10.5114/aoms.2020.98401.

9. Ortiz-Brizuela E, Villanueva-Reza M, González-Lara MF, et al. Clinical and epidemiological characteristics of patients diagnosed with COVID-19 in a tertiary care center in Mexico City: a prospective cohort study. Rev Invest Clin 2020; 72: 165-77.

10. Jackowska T, Wrotek A, Jankowski M, Pinkas J. Significant COVID-19 burden in Polish children. Arch Med Sci 2020. doi:10.5114/aoms.2020.98407.

11. Kammar-García A, Vidal-Mayo JJ, Vera-Zertuche JM, et al. Impact of comorbidities in Mexican SARS-CoV-2positive patients: a retrospective analysis in a national cohort. Rev Invest Clin 2020; 72: 151-8.

12. Bello-Chavolla OY, Bahena-López JP, Antonio-Villa NE, et al. Predicting mortality due to SARS-CoV-2: a mechanistic score relating obesity and diabetes to COVID-19 outcomes in Mexico. J Clin Endocrinol Metab 2020; 105: dgaa346.

13. Jordan RE, Adab P, Cheng KK. Covid-19: risk factors for severe disease and death. BMJ 2020; 368: m1198.

14. Selvan ME. Risk factors for death from COVID-19. Nat Rev Immunol 2020; 20: 407.

15. Rethemiotaki I. A preliminary study of coronavirus disease 2019 in China: the impact of cardiovascular disease on death risk. Arch Med Sci Atheroscler Dis 2020; 5: e219-23.

16. Daily database con COVID-19 tests in Mexico, freely available at: https://datos.gob.mx/busca/dataset/ informacion-referente-a-casos-covid-19-en-mexico/ resource/e8c7079c-dc2a-4b6e-8035-08042ed37165. Accessed: May 18, 2020.

17. Alegre-Díaz J, Herrington W, López-Cervantes M, et al. Diabetes and cause-specific mortality in Mexico City. N Engl J Med 2016; 375: 1961-71.

18. Gnatiuc L, Alegre-Díaz J, Wade R, et al. General and abdominal adiposity and mortality in Mexico city: prospective study of 150000 adults. Ann Intern Med 2019; 171: 397-405.

19. GBD 2013 Mortality and Causes of Death Collaborators. Global, regional, and national age-sex specific all-cause and cause-specific mortality for 240 causes of death, 1990-2013: a systematic analysis for the Global Burden of Disease Study 2013. Lancet 2015; 385: 117-71.

20. Katsiki N, Banach M, Mikhailidis DP. Lipid-lowering therapy and renin-angiotensin-aldosterone system inhibitors in the era of the COVID-19 pandemic. Arch Med Sci 2020; 16: 485-9.

21. Kopel J, Perisetti A, Roghani A, Aziz M, Gajendran M, Goyal H. Racial and gender-based differences in COVID-19. Front Public Health 2020; 8: 418.

22. Ferrante L, Fearnside PM. Protect Indigenous peoples from COVID-19. Science 2020; 368: 251.

23. Laurencin CT, McClinton A. The COVID-19 pandemic: a call to action to identify and address racial and ethnic disparities. J Racial Ethn Health Disparities 2020; 7 : 398-402.

24. Yaya S, Yeboah $\mathrm{H}$, Charles $\mathrm{CH}$, Otu A, Labonte R. Ethnic and racial disparities in COVID-19-related deaths: counting the trees, hiding the forest. BMJ Glob Health 2020; 5: e002913.

25. Jardim PTC, Dias IMÁV, Grande AJ, O’keeffe M, Dazzan P, Harding S. COVID-19 experience among Brasil's indigenous people. Rev Assoc Med Bras 2020; 66: 861-3.

26. Orlewska K, Klusek J. COVID-19 in Poland: potential associations with epidemiology, population and healthcare quality. Arch Med Sci 2020. doi:10.5114/aoms.2020.98236.

27. Garg S, Kim L, Whitaker M, et al. Hospitalization rates and characteristics of patients hospitalized with laboratory-confirmed coronavirus disease 2019 - COVID-NET, 14 States, March 1-30, 2020. MMWR Morb Mortal Wkly Rep 2020; 69: 458-64. 
E. Chiquete, J. Alegre-Díaz, A. Ochoa-Guzmán, L.N. Toapanta-Yanchapaxi, C. González-Carballo, A. Garcilazo-Ávila, R. Santacruz-Benitez, R. Ramírez-Reyes, R.M. Wong-Chew, G. Guerrero, M. Schmulson, J. Berumen, V. Sandoval-Rodríguez, E. Ruiz-Ruiz, C. Cantú-Brito

28. Kirby T. Evidence mounts on the disproportionate effect of COVID-19 on ethnic minorities. Lancet Respir Med 2020; 8: 547-8.

29. Papazafiropoulou AK, Antonopoulos S. The COVID-19 pandemic and diabetes mellitus. Arch Med Sci Atheroscler Dis 2020; 5: e200-5.

30. Shang L, Shao M, Guo Q, et al. Diabetes mellitus is associated with severe infection and mortality in patients with COVID-19: a systematic review and meta-analysis. Arch Med Res 2020: 51: 700-9.

31. Bianconi V, Bronzo P, Banach M, Sahebkar A, Mannarino MR, Pirro M. Particulate matter pollution and the COVID-19 outbreak: results from Italian regions and provinces. Arch Med Sci 2020; 16: 985-92.

32. Zhang Q, Yue Y, Tan H, Liu Y, Zeng Y, Xiao L. Single cell RNA-seq data analysis reveals the potential risk of SARS-CoV-2 infection among different respiratory system conditions. Front Genet 2020; 11: 942.

33. Yang X, Dai T, Zhou X, et al. Naturally activated adaptive immunity in COVID-19 patients. J Cell Mol Med 2020 Sep 25. doi: 10.1111/jcmm.15771. Epub ahead of print.

34. Schuchat A; CDC COVID-19 Response Team. Public Health Response to the Initiation and Spread of Pandemic COVID-19 in the United States, February 24-April 21, 2020. MMWR Morb Mortal Wkly Rep 2020; 69: 551-6.

35. Rivera-Dommarco J, Shamah-Levy T, Barrientos-Gutiérrez T, et al. The health of Mexicans living in localities with less than 100000 inhabitants. Salud Publica Mex 2019; 61: 709-15.

36. Denova-Gutiérrez E, Lopez-Gatell H, Alomia-Zegarra JL, et al. The association of obesity, type 2 diabetes, and hypertension with severe coronavirus disease 2019 on admission among Mexican patients. Obesity 2020; 28: 1826-32.

37. Azeez SA, Alhashim ZG, Al Otaibi WM, et al. State-ofthe-art tools to identify druggable protein ligand of SARS-CoV-2. Arch Med Sci 2020; 16: 497-507.

38. Olivares-Gazca JC, Priesca-Marín JM, Ojeda-Laguna M, et al. Infusion of convalescent plasma is associated with clinical improvement in critically ill patients with covid-19: a pilot study. Rev Invest Clin 2020; 72: 159-64.

39. Borgio JF, Alsuwat HS, Al Otaibi WM, et al. State-of-theart tools unveil potent drug targets amongst clinically approved drugs to inhibit helicase in SARS-CoV-2. Arch Med Sci 2020; 16: 508-18.

40. Baby K, Maity S, Mehta CH, Suresh A, Nayak UY, Nayak Y. Targeting SARS-CoV-2 main protease: a computational drug repurposing study. Arch Med Res 2020: S01884409(20)30957-7.

41. Reiner Ž, Hatamipour M, Banach M, et al. Statins and the COVID-19 main protease: in silico evidence on direct interaction. Arch Med Sci 2020; 16: 490-6.

42. Mesenburg MA, Restrepo-Mendez MC, Amigo H, et al. Ethnic group inequalities in coverage with reproductive, maternal and child health interventions: cross-sectional analyses of national surveys in 16 Latin American and Caribbean countries. Lancet Glob Health 2018; 6: e902-13. 